\title{
Factors affecting body awareness in older adults with chronic musculoskeletal pain
}

\author{
Emre Baskan, Nesrin Yagci, Ugur Cavlak
}

Kinikli Campus, School of Physical Therapy, Pamukkale University, Denizli, Turkey

Submitted: 12 April 2018; Accepted: 8 September 2018

Online publication: 17 July 2019

Arch Med Sci 2021; 17 (4): 934-939

DOI: https://doi.org/10.5114/aoms.2019.86614

Copyright @ 2019 Termedia \& Banach

\section{Abstract}

Introduction: Chronic musculoskeletal pain (CMP) and cognitive impairment (CI) may reduce body awareness in older adults. The first aim of this study was to determine the impact of CMP and $\mathrm{Cl}$ on body awareness in older adults. The second was to search for the factors most affecting body awareness using logistic regression analysis.

Material and methods: Two hundred and 65 older adults (males: 138 and females: 127 ) aged 65 and over (mean age; $72.27 \pm 6.42$ years) living in their own homes were included. We used the following evaluation methods: CMP intensity (Visual Analog Scale - VAS), cognitive status (Hodkinson's Abbreviated Mental Test - HAMT), and body awareness (Body Awareness Questionnaire - BAQ). Logistic regression analysis was used to determine the factor most affecting the BAQ score.

Results: Eighty-five point two percent of participants $(n=265)$ reported CMP (lower extremity pain: $74.6 \%$; spinal pain: $66.6 \%$; upper extremities pain: $44.4 \%$ ). CMP intensity was higher in lower extremities (mean VAS: 5.73 $\pm 1.86 \mathrm{~cm}$ ). Gender differences in terms of CMP were found in favor of males $(p=0.0001)$. Mean HAMT score was $8.16 \pm 1.65$. Gender difference in favor of males was significant $(p=0.0001)$. Mean BAQ score was 77.61 \pm 20.90 ; there was no significant difference between the gender $(p=0.142)$. There was a significant moderate positive correlation between body awareness and cognitive status $(r=0.382, p=0.0001)$. However, a weak negative correlation was found between body awareness and pain intensity $(r=-0.234$, $p=0.0001$ ). Regression analysis showed that living environment (rural area), low education level, low cognition level and increased CMP intensity significantly predicted body awareness.

Conclusions: The results obtained from this study indicate that cognitive impairment and pain should be reduced by improving body awareness among older adults. That is why health professionals should evaluate all related factors affecting body awareness before planning the most suitable rehabilitation program.

Key words: older adults, musculoskeletal pain, cognition, body awareness, logistic regression, chronic pain.

\section{Introduction}

Body awareness is our sense of our own bodies. It is an understanding of the parts that make up one's body, where they are located, how they feel, and even what they can do. Body awareness involves attention to and awareness of internal body sensations. Internal body awareness relies on receptors in joints, muscles, ligaments, and connective

\author{
Corresponding author: \\ Emre Baskan \\ School of Physical Therapy \\ Pamukkale University \\ Kinikli Campus \\ 20070 Denizli, Turkey \\ Phone: +902582964258 \\ Fax: +90 2582964494 \\ E-mail: ebaskan@pau.edu.tr
}


tissue [1]. In recent years, the construct of "body awareness" has emerged as a topic of scientific research across a wide range of disciplines. Body awareness has been proposed as one of the major mechanisms of mindfulness interventions, and it has been shown that chronic pain and depression are associated with decreased levels of body awareness [2-4].

Pain matrix includes, mainly, the somatosensory cortices the insular cortex, the anterior cingulate cortex and the thalamus. However, other cortical and subcortical regions such as the hippocampus, amygdala, basal ganglia and the cerebellum are typically implicated, depending upon the individual's set of circumstances [5]. This suggests that the pain experience may be different in each individual according to their own processing of pain $[5,6]$. The body awareness can affect some physiotherapeutic approaches and behavioral changes. It focuses on the basic function of movements related to posture, coordination, free breathing and awareness that constitutes the basis for the quality of movement in action, the expression of the self, interaction with others and involvement in activities in life. Body awareness therapies aim to integrate the body in the total experience of the self and to restore body awareness and body control [7].

Body awareness can be influenced by many factors. In recent years, especially in people with chronic pain, body awareness methods have become popular. There is limited research in the literature on body awareness and pain in the elderly.

The aim of the present study was to investigate the factors affecting body awareness in older adults with chronic musculoskeletal pain.

\section{Material and methods}

\section{Subjects}

This cross-sectional, comparative study was conducted in 265 older adults (males: 138 and females: 127) with musculoskeletal pain, aged 65 and over (mean age: $72.63 \pm 6.44$ years) who are living in their own homes in Denizli in Turkey. All participants were able to walk independently. All participants were visited and evaluated at their own home. Subjects who did not have any pain complaints, had cancer, used cholesterol medication [8] and did not want to participate in the study were not included our research. Musculoskeletal diseases that cause pain are commonly osteoarthritis, rheumatoid arthritis, cervical-lumbar discopathy, and sciatica. The educational level of the subjects was illiterate, primary and secondary education, high school and university. The level of education was calculated as years because there were also those who left education.

\section{Study design}

Data were collected via face-to-face interviews with the researchers. Socio-demographic data ascertained included age, gender, living environment, and educational level. All subjects were asked to respond to the remainder of the interview protocol, including measures of pain intensity, pain localization, cognitive function and body awareness. Outcome measures are described in more detail below. Ethics committee approval for the study was obtained from the Ethics Committee of Clinical Research, Pamukkale University (PAU60116787020/51818). All participants received information regarding the aim and methods of the study and provided their informed consent.

\section{Outcome measurements}

\section{Pain}

To determine the frequency of current pain, all eligible subjects were evaluated and asked to report whether they had had pain. The number of medications taken by subjects was also obtained. All participants were evaluated for severity of pain using an 11-point numeric visual analogue scale (VAS; $0=$ no pain; $10=$ worst pain imaginable). Participants were asked to characterize their pain intensity along a horizontal, 10-cm line. Participants who reported pain pinpointed it on a body diagram. Painful areas are classified as spine, upper extremity, or lower extremity.

\section{Cognitive function}

The Hodkinson Abbreviated Mental Test (HAMT) is used as a screening method to assess basic cognitive function in the elderly. In this test, each item is worth 1 point, and the total scores range from 0 to 10 correct answers. The HAMT is widely used by physical therapists and other health providers to detect mild cognitive impairment and dementia in the institutionalized elderly populations. It can be completed in approximately 3 min by older adults and includes components requiring intact short- and long-term memory attention, and orientation. A score of $\leq 6$ is associated with the best combination of sensitivity and specificity for the identification of cognitive impairment. This cutoff has been previously used to identify cognitive impairment in older persons [9].

\section{Body awareness}

The Body Awareness Questionnaire (BAQ) measures awareness of body processes. An 8-item subset of the 18-item scale was administered using a 5 -point Likert scale ( $1=$ not true of me, $5=$ very true of me). High scores indicate better body awareness [10]. 


\section{Statistical analysis}

Statistical analyses were conducted using SPSS for Windows version 17.0 (SPSS, Inc., Chicago, IL, USA). Frequencies were calculated for all variables, and data were presented as frequencies and percentages or mean and standard deviation. Independent samples $t$ test was used to reveal differences between the groups. Correlations between the BAQ scores, socio-demographic data, and HAMT scores were analyzed using Pearson's and Spearman's correlation coefficients. Multivariate logistic regression analyses were performed to determine the factors most affecting body awareness scores. $P$-values $<0.05$ were considered as significant.

\section{Results}

Participants were 265 older male $(n=138)$ and female $(n=127)$ subjects with musculoskeletal pain. Socio-demographic data are presented in Table I. The majority of male participants lived in an urban area (63\%). The majority of the sample had a low level of education (69.4\%) and reported taking medication (75.4\%).

Clinical features of the sample are presented in Table II. There were no gender differences in pain localization (spinal pain, upper extremity, lower extremity). Lower extremity pain intensity scores were higher in female than male participants $(p=$ 0.001); whereas HAMT scores were higher in male than female participants $(p=0.0001)$. There was no difference between the genders in $\mathrm{BAQ}$ score $(p=0.142)$ and upper extremity $(p=0.397)$ VAS scores.

Results of the correlation analysis are shown in Table III. There were significant, moderate positive correlations between body awareness and cognition, and weak positive correlations with education level $(r=0.382, p=0.0001 ; r=0.238, p=$ 0.0001 , respectively). A significant weak negative correlation was found between body awareness and pain severity, and a negligible correlation with the number of medications taken $(r=-0.234, p=$ $0.0001 ; r=-0.147 p=0.0001)$. There was a significant negative weak correlation between living area and pain score $(r=-0.206, p=0.000)$, and there were significant positive weak correlations between living area and education level $(r=0.297$, $p=0.000)$ and BAQ score $(r=-0.201, p=0.001)$

Results of the multivariate logistic regression analysis are presented in Table IV. Cognitive status (HAMT score), musculoskeletal pain intensity (VAS score) and education level have been determined as factors related to body awareness. In this analysis, living environment (rural area), low education level, low cognition level (HAMT score) and increased musculoskeletal pain intensity were the most negative factors for body awareness.

\section{Discussion}

Musculoskeletal conditions are the most common cause of severe long-term pain and physical disability. The prevalence of musculoskeletal conditions increases markedly with age [11]. Musculoskeletal conditions are also the main cause of

Table I. Socio-demographic characteristics of study sample

\begin{tabular}{|c|c|c|c|}
\hline Characteristics & Female $(n=127)$ & Male $(n=138)$ & Total $(n=265)$ \\
\hline $\begin{array}{l}\text { Age, mean (SD) } \\
\text { [years] }\end{array}$ & $72.06(5.99)$ & $72.42(5.90)$ & $72.25(5.94)$ \\
\hline $\begin{array}{l}\text { BMI, mean (SD) } \\
{\left[\mathrm{kg} / \mathrm{m}^{2}\right]}\end{array}$ & $28.44(4.93)$ & $26.31(3.49)$ & $27.33(4.37)$ \\
\hline \multicolumn{4}{|c|}{$\begin{array}{l}\text { Living environment, } \\
n(\%):\end{array}$} \\
\hline Rural & $56(44.1)$ & $51(37)$ & $107(40.4)$ \\
\hline Urban & $71(55.9)$ & $87(63)$ & $158(59.6)$ \\
\hline \multicolumn{4}{|c|}{ Education level, $n(\%)$ : } \\
\hline Illiterate & $50(39.4)$ & $10(7.2)$ & $60(22.7)$ \\
\hline $1-8$ years & $72(56.7)$ & $112(81.2)$ & $184(69.4)$ \\
\hline$>8$ years & $5(3.9)$ & $16(11.6)$ & $21(7.9)$ \\
\hline \multicolumn{4}{|c|}{$\begin{array}{l}\text { Drug consumption, } \\
n(\%):\end{array}$} \\
\hline Yes & $104(81.9)$ & $96(69.5)$ & $200(75.4)$ \\
\hline No & $23(18.1)$ & $42(30.5)$ & $65(24.6)$ \\
\hline
\end{tabular}

$B M I$ - body mass index, SD - standard deviation 
Table II. Clinical features of the samples $(n=265)$

\begin{tabular}{|lcccc|}
\hline Variables & Total & Female & Male & $P$-value \\
\hline Pain localization, $n(\%):$ & & & \\
\hline Spinal & $207(66.6)$ & $103(49.8)$ & $104(50.2)$ & NS \\
\hline Upper ext. & $134(44.4)$ & $66(47.8)$ & $72(52.2)$ & NS \\
\hline Lower ext. & $232(74.6)$ & $119(51.3)$ & $113(48.7)$ & NS \\
\hline Pain intensity, mean (SD)** : & & & 0.078 \\
\hline Spinal VAS & $5.30(1.74)$ & $5.51(1.85)$ & $5.08(1.59)$ & 0.397 \\
\hline Upper ext. VAS & $4.26(1.67)$ & $4.39(1.76)$ & $4.15(1.58)$ & 0.001 \\
\hline Lower ext. VAS & $5.73(1.86)$ & $6.12(1.94)$ & $5.78(2.35)$ & 0.0001 \\
\hline HAMT** & $8.16(1.65)$ & $7.77(1.61)$ & $8.51(1.62)$ & 0.142 \\
\hline BAQ ${ }^{* *}$ & $77.61(20.90)$ & $75.70(20.31)$ & $79.46(21.42)$ & \\
\hline
\end{tabular}

SD - standard deviation, VAS - Visual Analog Scale, ext. - Extremity, HAMT - Hodkinson's Abbreviated Mental Test, BAQ - Body Awareness Questionnaire, NS - not significant. *Independent sample t-test, ${ }^{* *} \chi^{2}$ test.

Table III. Correlations between body awareness, age, body mass index, education, drug consumption, pain intensity and cognition $(n=265)$

\begin{tabular}{|c|c|c|c|c|c|c|c|}
\hline & BAQ & Age & BMI & Education & NM & VAS & HAMT \\
\hline BAQ & - & & & & & & \\
\hline Age & -0.109 & - & & & & & \\
\hline BMI & 0.053 & $-0.135^{\star}$ & - & & & & \\
\hline Education & $0.216^{\star \star}$ & $-0.269^{* *}$ & -0.049 & - & & & \\
\hline NM & $-0.147^{\star}$ & 0.096 & 0.035 & -0.065 & - & & \\
\hline VAS & $-0.249^{\star \star}$ & 0.049 & 0.088 & $-0.156^{*}$ & $0.299^{* *}$ & - & \\
\hline HAMT & $0.382^{* \star}$ & $-0.297^{\star *}$ & 0.046 & $0.477^{\star \star *}$ & -0.065 & $-0.234^{\star \star}$ & - \\
\hline
\end{tabular}

BMI - body mass index, VAS - Visual Analogue Scale, ext. - extremity, HAMT - Hodkinson's Abbreviated Mental Test, BAQ - Body Awareness Questionnaire, NM - number of medications. ${ }^{*} p<0.05,{ }^{* *} p<0.0001$. All variables except education were correlated with each other according to Pearson's method. Education was correlated with other variables using Spearman's method.

Table IV. Multivariate logistic regression analyses for body awareness $(n=265)$

\begin{tabular}{|lccccc|}
\hline $\begin{array}{l}\text { Independent } \\
\text { variables }\end{array}$ & B & SE & $\beta$ & $t$ & $P$-value* \\
\hline Age [years] & -0.18 & 0.246 & -0.052 & 0.074 & 0.46 \\
\hline BMI & -0.09 & 0.132 & 0.047 & 0.706 & 0.48 \\
\hline Education & 2.108 & 1.24 & 0.125 & 1.694 & 0.009 \\
\hline NM & -0.57 & 0.546 & -0.07 & -1.04 & 0.3 \\
\hline VAS & -2.11 & 0.879 & -0.167 & -2.4 & 0.02 \\
\hline HAMT & 3.312 & 0.931 & 0.267 & 3.56 & 0.0001 \\
\hline
\end{tabular}

BMI - body mass index, VAS - Visual Analog Scale, ext. - extremity, HAMT - Hodkinson's Abbreviated Mental Test, BAQ - Body Awareness Questionnaire, NM - number of medications. *Multivariate logistic regression analysis was used.

disability among older age groups. The pain and physical disability resulting from musculoskeletal conditions negatively affect social functioning and mental health, further diminishing patients' quality of life [12].
Mindfulness-based interventions have recently been shown to be effective for the treatment of chronic pain with a small to moderate effect on pain and depression [13]. On the other hand, emotional awareness is linked to better clinical 
outcomes and quality of life. It is reduced by depressive symptoms and depression-related affective and cognitive outcomes [14-18]. Cognitive impairment is commonly associated with the pain experience. This impairment represents a major obstacle to daily activities and rehabilitation, especially in individuals with chronic pain $[19,20]$. Chronic musculoskeletal pain is a highly prevalent and often disabling condition among older adults, who are also affected by deficiencies of cognition and body awareness [21-23].

A major review of the research on gender, age, and pain found that women experience more pain compared to men and that the pain they experience increases with age $[24,25]$. Another study reported that women experience pain more often than men [26]. Gender differences were statistically significant in terms of musculoskeletal pain only.

Our study examined 265 elderly people with musculoskeletal pain. We observed that increased age is an important factor leading to pain experienced in the spinal column and lower extremities $(p<0.001)$. In particular, we found that lower extremity pain is more common in women than in men. We believe that the main explanation was a higher mean body mass index (BMI) in female participants and this increased weight causes more load in the legs and joints. As a result, there are more degenerative changes in the bone and joint structures of these people. On the other hand, we noted that upper extremity pain was lower than other pain localization $(p<0.000)$.

Older adults' cognitive performance affects daily living and it is accepted as a strong predictor of mortality [27]. Dirik et al. [28] found that women experienced more cognitive impairment with age compared to men; whereas other studies have shown that cognitive impairment increased with age in both men and women [27, 29]. In our study, HAMT score varied with age, and men had higher scores on this cognitive test than women. These results suggest that older women experience more cognitive decline with age than men. The elderly women evaluated in our study had a low level of education and all were housewives. Finally, although musculoskeletal pain was found to be a common problem in our study, no gender differences were found in terms of pain localization.

Body awareness can be adaptive or maladaptive in much the same way that pain can be adaptive or maladaptive. We base our argument largely on previous pain literature, and have examined certain factors that influence body awareness [2]. Although the related literature on this issue shows that many factors affect body awareness, our regression analyses showed that certain related factors (including age, gender, and BMI) did not significantly predict body awareness in our sample of older adults. On the other hand, some factors such as cognitive status, pain intensity, and education level were identified as related factors to body awareness in our study. We found relationships between body awareness and living area. At the same time educational level affected the body awareness. People living in the city had a higher level of body awareness values and education levels. This may help us to approach the pain, but our findings have poor correlations, so more research needs to be done on this topic.

In some cases there were other diseases besides musculoskeletal diseases (e.g. hypertension, biliary stones). This is a limitation of our work.

In conclusion, the results obtained from this study indicate that in order to affect body awareness in older adults, cognitive impairments and pain should be reduced. Correspondingly, physiotherapists working with older adults should focus on pain intensity and cognitive impairment in order to plan the most suitable physiotherapy program for older adult patients.

The findings of this study show that there are many determining factors, such as cognitive impairment, chronic musculoskeletal pain, education level, and living environment. A geriatric rehabilitation program taking into accent all related factors identified in this study to affect body awareness of older adults is vital.

\section{Acknowledgments}

The authors would like thank Dr. Hande Senol for statistical analysis of the research.

\section{Conflict of interest}

The authors declare no conflict of interest.

\section{References}

1. Mehling W, Wrubel J, Daubenmier J, et al. Body awareness: a phenomenological inquiry into the common ground of mind-body therapies. Philos Ethics Humanit Med 2011; 6: 6 .

2. Mehling W, Gopisetty V, Daubenmier J, Price C, Hecht F, Stewart A. Body awareness: construct and self-report measures. PLoS One 2009; 4: e5614.

3. Mehling WE, Daubenmier J, Price CJ, Acree M, Bartmess E, Stewart AL. Self-reported interoceptive awareness in primary care patients with past or current low back pain. J Pain Res 2013; 2013: 403-18.

4. de Jong M, Lazar S, Hug K, et al. Effects of mindfulness-based cognitive therapy on body awareness in patients with chronic pain and comorbid depression. Front Psychol 2016; 7: 967.

5. Bingel, U, Tracey, I. Imaging CNS modulation of pain in humans. Physiology 2008; 23: 371-80.

6. Ribera d'Alcalà C, Webster D, Esteves J. Interoception, body awareness and chronic pain: results from a case-control study. Int J Osteopathic Med 2015; 18 : 22-32. 
7. Gunel MK, Yağli NV, Kerem Günel M, et al. Effect of body awareness therapy on fibromyalgia syndrome in women: a randomized controlled trial. J Exercise Ther Rehabil 2014; 2: 43-8.

8. Bingel U, Tracey I. Imaging CNS modulation of pain in humans. Physiology 2008; 23: 371-80.

9. Hodkinson $\mathrm{H}$. Evaluation of a mental test score for assessment of mental impairment in the elderly. Age Ageing 2012; 41 (Suppl 3): iii35-40.

10. Shields S, Simon A. Is awareness of bodily change in emotion related to awareness of other bodily processes? J Pers Assess 1991; 57: 96-109.

11. Rustøen T, Wahl A, Hanestad B, Lerdal A, Paul S, Miaskowski C. Age and the experience of chronic pain. Clin J Pain 2005; 21: 513-23.

12. Woolf A. Driving musculoskeletal health for Europe: EUMUSC.NET. Reumatismo 2011; 63: 1-4.

13. Veehof M, Trompetter H, Bohlmeijer E, Schreurs K. Acceptance- and mindfulness-based interventions for the treatment of chronic pain: a meta-analytic review. Cogn Behav Ther 2016; 45: 5-31.

14. Burger A, Lumley M, Carty J et al. The effects of a novel psychological attribution and emotional awareness and expression therapy for chronic musculoskeletal pain: a preliminary, uncontrolled trial. J Psychosom Res 2016; 81: 1-8.

15. Mankus A, Boden M, Thompson R. Sources of variation in emotional awareness: age, gender, and socioeconomic status. Pers Individ Dif 2016; 89: 28-33.

16. Goldman R, Greenberg L, Pos A. Depth of emotional experience and outcome. Psychother Res 2005; 15: 248-60.

17. Arch J, Craske M. Mechanisms of mindfulness: emotion regulation following a focused breathing induction. Behav Res Ther 2006; 44: 1849-58.

18. Farb NA, Anderson AK, Mayberg H, Bean J, McKeon D, Segal ZV. Mindfulness training alters the neural expression of sadness. Emotion 2010; 10: 25-33.

19. van Hecke O, Torrance N, Smith B. Chronic pain epidemiology and its clinical relevance. Br J Anaesth 2013; 111: 13-8.

20. Moriarty O, McGuire B, Finn D. The effect of pain on cognitive function: a review of clinical and preclinical research. Prog Neurobiol 2011; 93: 385-404.

21. Helme R, Gibson S. The epidemiology of pain in elderly people. Clin Geriatr Med 2001; 17: 417-31.

22. Gauthier S, Reisberg B, Zaudig M, et al. Mild cognitive impairment. Lancet 2006; 367: 1262-70.

23. Hansell S, Sherman G, Mechanic D. Body awareness and medical care utilization among older adults in an $\mathrm{HMO}$. J Gerontol 1991; 46: S151-9.

24. Mänty M, Thinggaard M, Christensen K, Avlund K. Musculoskeletal pain and physical functioning in the oldest old. Eur J Pain 2014; 18: 522-9.

25. Fillingim R, King C, Ribeiro-Dasilva M, Rahim-Williams B, Riley J. Sex, gender, and pain: a review of recent clinical and experimental findings. J Pain 2009; 10: 447-85.

26. Ho A, Ashe M, DeLongis A, Graf P, Khan K, Hoppmann C. Gender differences in pain-physical activity linkages among older adults: lessons learned from daily life approaches. Pain Res Manag 2016; 2016: 1931590.

27. Tilvis R, Kähönen-Väre MH, Jolkkonen J, Valvanne J, Pitkala K, Strandberg T. Predictors of cognitive decline and mortality of aged people over a 10-year period. J Gerontol A Biol Sci Med Sci 2004; 59: 268-74.
28. Dirik A, Cavlak U, Akdag B. Identifying the relationship among mental status, functional independence and mobility level in Turkish institutionalized elderly: gender differences. Arch Gerontol Geriatr 2006; 42: 339-50.

29. Samuel R, McLachlan C, Mahadevan U, Isaac V. Cognitive impairment and reduced quality of life among old-age groups in Southern Urban India: home-based community residents, free and paid old-age home residents. QJM 2016; 109: 653-9. 